\title{
Políticas públicas para o enfrentamento do HIV / AIDS em países com sistema universal e gratuito de saúde: uma análise segundo a UNAIDS
}

Public policies for coping with HIV / AIDS in countries with a universal and free health system: an analysis according to UNAIDS

Politicas publicas para enfrentar el VIH / SIDA en paises con un sistema de salud universal y gratuito: un análisis según ONUSIDA

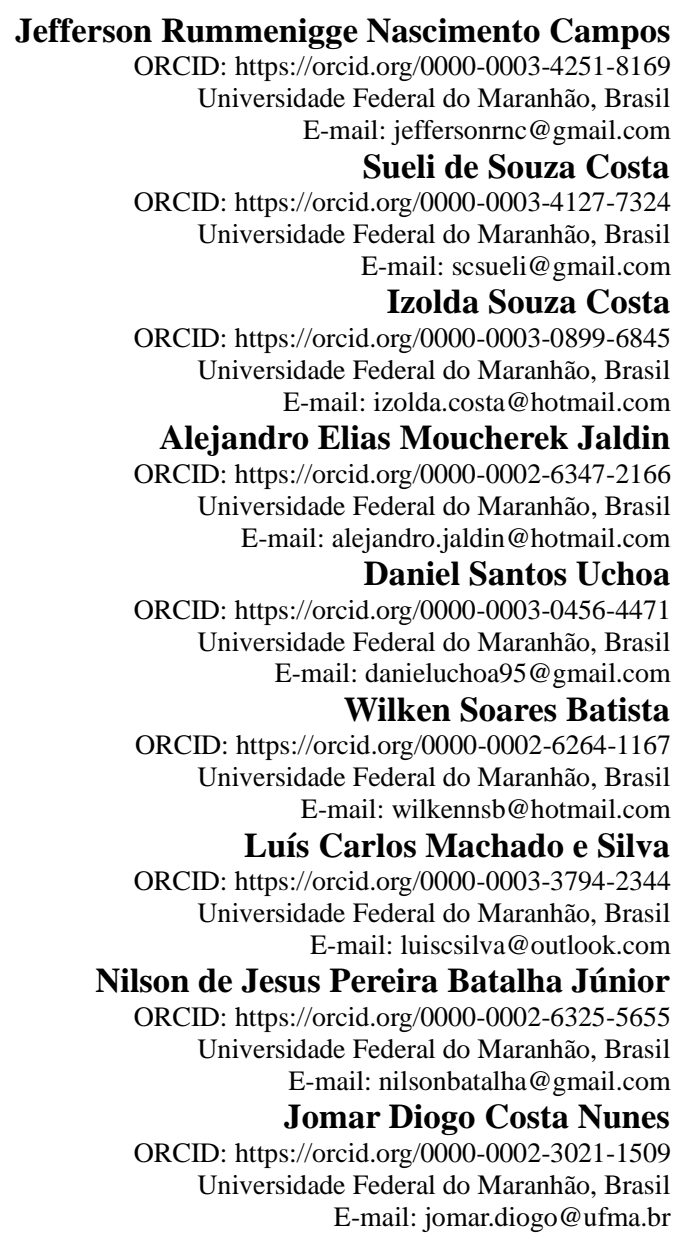

\begin{abstract}
Resumo
Esse artigo objetivou realizar análise comparativa das políticas públicas de saúde direcionadas ao combate ao HIV/AIDS nos países com sistema de saúde universal e gratuito, para o cumprimento das metas da UNAIDS. Foram utilizados dados obtidos na plataforma online da UNAIDS, referente ao ano de 2019, das seguintes variáveis: Teste de HIV; Terapia Antirretroviral; Regimes de Terapia Antirretroviral; Carga viral; Resistência à Drogas; Adesão e Retenção; Leis; Profilaxia Pré-Exposição; Sistema de Informação; Mortalidade; 90-90-90; Tuberculose/HIV. Diante das variáveis analisadas, os resultados apontaram que somente o Brasil e o Canadá apresentavam dados consolidados na plataforma. Concluiu-se que o país que apresenta os dados melhor consolidados e alinhado às recomendações da Organização Mundial da Saúde (OMS) é o Brasil, entre os que possuem sistema universal e gratuito de saúde, nos parâmetros avaliados. Este trabalho demonstra a importância e os esforços dos países em seguir as recomendações da OMS para o enfrentamento desse vírus, bem como evidencia uma problemática relacionada à coleta ou disponibilidade dos dados, pois somente o Brasil e o Canadá apresentavam dados disponibilizados na plataforma.
\end{abstract}

Palavras-chave: Políticas públicas de saúde; HIV; Síndrome da Deficiência Imunológica Adquirida; Saúde pública. 


\begin{abstract}
This article aimed to carry out a comparative analysis of public health policies aimed at combating HIV / AIDS in countries with a universal and free health system, in order to meet the UNAIDS goals. Data obtained from the UNAIDS online platform, for the year 2019, of the following variables were used: HIV test; Antiretroviral Therapy; Antiretroviral Therapy Regimes; Viral charge; Drug Resistance; Adhesion and Retention; Laws; Pre-exposure prophylaxis; Information system; Mortality; 90-90-90; Tuberculosis / HIV. In view of the variables analyzed, the results showed that only Brazil and Canada presented consolidated data on the platform. It was concluded that the country that presents the best consolidated data and aligned with the recommendations of the World Health Organization (WHO) is Brazil, among those that have a universal and free health system, in the evaluated parameters. This work demonstrates the importance and efforts of countries to follow the WHO recommendations to face this virus, as well as showing a problem related to the collection or availability of data, as only Brazil and Canada presented data available on the platform.
\end{abstract}

Keywords: Public health policy; HIV; Acquired Immunodeficiency Syndrome; Public health.

\title{
Resumen
}

Este artículo tuvo como objetivo realizar un análisis comparativo de las políticas de salud pública destinadas a combatir el VIH / SIDA en países con un sistema de salud universal y gratuito, con el fin de cumplir con los objetivos de ONUSIDA. Se utilizaron datos obtenidos de la plataforma online ONUSIDA, para el año 2019, de las siguientes variables: prueba de VIH; Terapia antirretroviral; Regímenes de terapia antirretroviral; Carga viral; Resistencia a las drogas; Adhesión y Retención; Leyes; Profilaxis previa a la exposición; Sistema de información; Mortalidad; 90-9090; Tuberculosis / VIH. A la vista de las variables analizadas, los resultados mostraron que solo Brasil y Canadá presentaron datos consolidados en la plataforma. Se concluyó que el país que presenta los mejores datos consolidados y alineados con las recomendaciones de la Organización Mundial de la Salud (OMS) es Brasil, entre los que cuentan con un sistema de salud universal y gratuito, en los parámetros evaluados. Este trabajo demuestra la importancia y el esfuerzo de los países por seguir las recomendaciones de la OMS para enfrentar este virus, además de mostrar un problema relacionado con la recolección o disponibilidad de datos, ya que solo Brasil y Canadá presentaron datos disponibles en la plataforma.

Palabras clave: Políticas públicas de salud; VIH; Síndrome de Inmunodeficiencia Adquirida; Salud pública.

\section{Introdução}

O Vírus da Imunodeficiência Humana (HIV) revela-se, ainda atualmente, um problema relevante em saúde pública tanto a nível nacional, quanto mundial. Estima-se que desde a sua descoberta houveram mais de 35 milhões de óbitos relacionados à doença, e que, em 2016, ele estaria relacionado à morte de pelo menos 1 milhão de pessoas no mundo (OPAS/OMS, 2017).

No Brasil, o primeiro caso envolvendo o HIV foi identificado no início da década de 80 e, em 1986, o Ministério da Saúde iniciou suas campanhas de prevenção e combate ao HIV através do Programa Nacional de DST e AIDS, que teve grande relevância para os avanços tecnológicos, tanto para o primeiro isolamento do HIV-1 pela Fundação Oswaldo Cruz (FIOCRUZ), quanto pelo início do tratamento com a Zidovudina (AZT) (FIOCRUZ, [201-]; Brasil, 2018).

Naquele momento, no Brasil, houve uma mudança no direcionamento das Políticas Públicas, com instituição da lei que garantiu a distribuição gratuita dos medicamentos antirretrovirais (ARV) de maneira universal, ajudando assim a reduzir os preconceitos e a desfazer a relação HIV e morte do indivíduo (Agostini et al., 2019).

No final de 2015, calcula-se que pelo menos 17 milhões de pessoas no mundo tiveram acesso a um grupo de medicamentos com função de antirretrovirais (ONU, 2016a). Tais medicações, no Brasil, são distribuídas gratuitamente desde a década de 90 e ao longo desse período passaram por vários processos de aprimoramento (Nunes Júnior \& Ciosak, 2018).

Nesse contexto, surgiu o Joint United Nations Programme on HIV/AIDS (UNAIDS), uma força conjunta da Organização das Nações Unidas (ONU), Organização Mundial da Saúde (OMS) e vários outros órgãos internacionais, que estimula, induz e ajuda os países a atingirem o acesso à prevenção, tratamento e cuidados no que tange ao HIV/AIDS. Objetiva, ainda, elaborar programas de intervenção e implementá-los para que se alcance a zero infecção, estigma, discriminação e mortes relacionadas ao HIV/AIDS (ONU, 2016b).

No Brasil, de acordo com a Constituição Federal de 1988, a saúde é garantida pelo Estado e baseada na 
universalidade, integralidade e equidade (Brasil, 1988). A saúde passou a ser direito de todos e dever do Estado provê-la, por meio de políticas gratuitas de saúde de cunho social e econômico, a fim de reduzir o risco de doenças e outros agravos, além de serviços de promoção, proteção e recuperação, nascendo o Sistema Único de Saúde (SUS) e a estruturação dos serviços de saúde vigentes. Assim, o acesso à saúde é disponibilizado desde a população geral, quanto aos grupos que necessitam de atenção direcionada (Menezes et al., 2017).

No mundo, existem outros países que direcionam e distribuem sua atenção em saúde de maneira gratuita e universal, e dentre eles podem ser destacados a Austrália, o Canadá, a França, o Reino Unido e a Suécia (SIMERS, 2016). Entretanto, apesar de oferecerem serviços de maneira gratuita, apresentam particularidades no combate à infecção pelo HIV e tratamento da AIDS.

No Canadá, o Canada's Health Care System apresenta-se como um serviço público e dinâmico, onde os serviços de saúde são baseados na atenção primária e o atendimento em medicina é voltado para a clínica e de modo individualizado. Entretanto, apesar dos serviços de saúdes oferecidos pelos governos locais, alguns serviços não estão incluídos de maneira gratuita, tal como saúde bucal, medicamentos extra-hospitalares e atendimento de outros profissionais da saúde (Brandão, 2019; Canadá, 2019).

$\mathrm{Na}$ Austrália, o sistema de saúde é similar ao empregado no Canadá, pois esse serviu de modelo devido algumas semelhanças tais como o Produto Interno Bruto (PIB) do país, extensão geográfica e baixa densidade populacional. O sistema adotado é conhecido como Medicare e representa dois terços do atendimento em saúde. Entretanto, quase metade da população custeia serviços privados (Duckett, 2018).

$\mathrm{Na}$ Suécia, o sistema de saúde é gratuito, descentralizado e subsidiado por meio dos impostos. Nesse sistema, o indivíduo que desejar atendimento, deve iniciar obrigatoriamente no seu Vârdcentral (Centro de Cuidados), unidade básica de saúde no modelo brasileiro, onde está cadastrado e passará pela triagem de um médico generalista ou enfermeiro, exceto em casos que envolva emergências, nos quais o atendimento acontece diretamente nos hospitais (Sweden, 2017).

No Reino Unido, o National Health System (NHS) foi fundado na década de 40 e serviu de modelo para a criação do SUS. Nesse sistema, o atendimento aborda a universalidade e gratuidade do acesso e apresenta-se de modo descentralizado, pois a atenção básica é apresentada como local de acesso para ingressar no sistema de saúde, no qual a população conta com o atendimento de um clínico geral e, de acordo com a necessidade, esse encaminha o paciente a especialista ou atendimento especializado. Ademais, conta com hospitais e postos de atendimentos 24h para casos urgentes (SIMERS, 2016). O Reino Unido é composto por: Inglaterra, Escócia, País de Gales e Irlanda do Norte. Desses, o NHS da Inglaterra é o que mais recebe recursos do Departamento de Saúde do Reino Unido (Garcia \& Gonçalves, 2020).

O combate ao HIV/AIDS exige novas diligências e afirmação do governo, estimulo à comunidade técnico-científica e mudanças no engajamento e cooperação da sociedade. No que tange ao Brasil, desde o início da epidemia até o final do ano de 2018, foram notificados mais de 330 mil casos de óbitos relacionados ao HIV/AIDS. Apesar de elevado número de óbitos, a taxa de mortalidade apresentou uma redução de aproximadamente 25\% entre o ano de 2008 a 2018 (Brasil, 2018).

A UNAIDS, em 2014, criou a meta 90-90-90, que estabelece que em 2020 90\% das pessoas portadoras do HIV deveriam estar diagnosticadas, das quais $90 \%$ em uso dos medicamentos antirretrovirais e que $90 \%$ possuam carga viral indetectável. Essas medidas visam acabar com a epidemia até 2030 (Brasil, 2018).

Atualmente, entre as formas de prevenção pode-se destacar as biomédicas, que consistem na utilização do método clássico; uso de preservativos masculinos, femininos e lubrificantes; e intervenções biomédicas centradas na utilização de antirretrovirais (ARV). Esse último pode ser dividido em Tratamento como prevenção (TasP), Profilaxia Pós-Exposição (PEP) e a Profilaxia Pré-Exposição - PrEP (Brasil, [201-]a).

$\mathrm{O}$ TasP consiste na utilização dos ARV da maneira correta e concede às pessoas que vivem com HIV (PVH) a chance 
de obter a "carga viral indetectável". Esse fato está relacionado a uma melhora na qualidade de vida e menor possibilidade de transmitir o vírus à outra pessoa (ONU, [201-]).

A PEP se baseia na utilização de ARV, que tem a finalidade de evitar a replicação viral no organismo do indivíduo exposto a situações de risco e que possa ter tido contato com o vírus (Violência Sexual, Relação Desprotegida ou Acidente Ocupacional); devendo ser utilizada até 72 horas do evento e com duração ininterrupta de 28 dias.

A PrEP é destinada a pessoas que intencionalmente se expõem a eventuais riscos de contaminação pelo HIV: Práticas Sexuais, Contextos de Vulnerabilidade, Populações com elevada prevalência do HIV e Parcerias Sexuais (Brasil, 2018).

A terapia antirretroviral tem por finalidade diminuir a morbimortalidade e aumento da expectativa e qualidade de vida da PVH. O uso regular das medicações é capaz de reduzir em $96 \%$ a chance de contaminação na prática sexual e deve ser iniciada após o esclarecimento do risco e benefício de sua utilização, e não deve ser interrompida. As medicações recomendadas como primeira linha são Tenofovir (TDF), Lamivudina (3TC) e Dolutegravir (DTG), para adultos e adolescentes sem contraindicações (Brasil, 2018).

Uma importante relação no que diz respeito ao HIV, é sua relação com a tuberculose (TB), sendo um relevante problema de saúde pública. Estima-se que, em 2015, dos 1,4 milhões de mortes ocasionadas pela TB no mundo, aproximadamente $29 \%$ dos indivíduos eram coinfectados pelo HIV. Esses números estão relacionados a não adesão ao tratamento ou abandono, e induzem à resistência às medicações (WHO, 2016; Miranda et al., 2017).

Assim, tendo em vista o impacto social, biológico e financeiro causado pela infecção do HIV/AIDS, faz-se necessário analisar e comparar os países que, como o Brasil, possuem políticas de saúde gratuitas e bem definidas cadastrados na plataforma da UNAIDS (como França, Canadá, Austrália, Suécia e Reino Unido) a fim de destacar o país que mais se alinha com as Diretrizes da OMS de acordo com a UNAIDS, além de estabelecer ou estimular a incorporação de medidas que poderão repercutir positivamente na abordagem da doença.

\section{Metodologia}

Estudo observacional analítico ecológico, qualitativo (Pereira, Shitsuka, Parreira, \& Shitsuka, 2018), que comparou as variáveis de políticas públicas de saúde relacionadas ao HIV, em países que possuem o acesso universal e gratuito ao Sistema de Saúde, utilizando dados disponíveis na plataforma online da UNAIDS referentes ao ano de 2019 e foram coletados em conjunto com a OMS, representando a compilação da informação gerada por 174 países envolvendo 50 variáveis.

Foram abordados os seguintes países: Austrália, Brasil, Canadá, França, Reino Unido e Suécia. Com a catalogação dos dados, foram elaborados quadros para análise qualitativa, comparando-se as variáveis: Teste de HIV; Terapia Antirretroviral; Regimes de Terapia Antirretroviral; Carga viral; Resistência à Drogas; Adesão e Retenção; Leis; Profilaxia Pré-Exposição; Sistema de Informação; Mortalidade; 90-90-90; Tuberculose/HIV.

Por se tratarem de dados de livre acesso no site da UNAIDS, na internet, este trabalho foi dispensado de apresentação ao Comitê de Ética e Pesquisa, de acordo com a Resolução 466/2012 do Conselho Nacional de Saúde, do Ministério da Saúde do Brasil.

\section{Resultados}

Dos países analisados, apenas o Brasil e o Canadá apresentam dados disponibilizados na plataforma da UNAIDS, sendo que o primeiro adotou completamente as recomendações da OMS em 2015 sobre a testagem do HIV, enquanto o segundo as implementou de maneira parcial. Os outros países (Austrália, França e Suécia), não possuíam dados disponibilizados no ano de 2019. No tocante à política de provisão gratuidade total, para públicos direcionados ou custeada, somente os dados do Brasil e Canadá estavam disponíveis e ambos fornecem seus testes de HIV de modo universal e sem 
custos (Quadro 1).

Quadro 1. Adoção de recomendações das diretrizes da OMS 2015 e política de provisão de testes de HIV gratuita.

\begin{tabular}{|c|c|c|}
\hline Países & $\begin{array}{l}\text { O país adotou as recomendações das diretrizes da } \\
\text { OMS de 2015 sobre os serviços de teste de HIV }\end{array}$ & $\begin{array}{l}\text { Política de provisão de testes de HIV gratuita } \\
\text { para todos, gratuita para alguns ou a um custo }\end{array}$ \\
\hline Austrália & Dados não disponíveis & Dados não disponíveis \\
\hline Brasil & Sim, completamente & Gratuito para todos \\
\hline Canadá & Sim, parcialmente & Gratuito para todos \\
\hline França & Dados não disponíveis & Dados não disponíveis \\
\hline Reino Unido & Dados não disponíveis & Dados não disponíveis \\
\hline Suécia & Dados não disponíveis & Dados não disponíveis \\
\hline
\end{tabular}

Fonte: UNAIDS (2020).

Quanto às Diretrizes Consolidadas da OMS de 2018 adaptas ao uso de ARVs para o tratamento e infecção por HIV, apenas o Brasil completou as exigências. Com relação ao Canadá, esse apresentou o status "Outro" como dado contido na plataforma. Ademais, apenas o Brasil apresenta uma política nacional de testagem para a carga viral de rotina, em pacientes adultos e adolescentes, totalmente implementada (Quadro 2).

Quadro 2. Terapia antirretroviral e carga viral: diretrizes e políticas de teste.

\begin{tabular}{|c|c|c|}
\hline Países & $\begin{array}{l}\text { Diretrizes consolidadas da OMS de 2018 adaptadas ao } \\
\text { país sobre o uso de ARVs para o tratamento e e } \\
\text { prevenção da infeção por HIV }\end{array}$ & $\begin{array}{l}\text { Política nacional de teste de carga viral } \\
\text { de rotina: para adultos e adolescentes }\end{array}$ \\
\hline Austrália & Dados não disponíveis & Dados não disponíveis \\
\hline Brasil & Sim, completou & Sim, totalmente implantada \\
\hline Canadá & Outro & Nenhuma política de teste \\
\hline França & Dados não disponíveis & Dados não disponíveis \\
\hline Reino Unido & Dados não disponíveis & Dados não disponíveis \\
\hline Suécia & Dados não disponíveis & Dados não disponíveis \\
\hline
\end{tabular}

Fonte: UNAIDS (2020).

Somente o Brasil adota como primeira linha o TDF/3TC ou (FTC)/ EFV para início dos tratamentos nas diretrizes nacionais para adultos e adolescentes. Além disso, no que tange à Resistência a Drogas, na qual enfatiza se foi implementado algum sistema para monitorar a resistência aos medicamentos antirretrovirais, apenas o Brasil e Canadá possuem esses dados disponibilizados e fazem esse monitoramento (Quadro 3).

Quadro 3. Regimes da terapia antirretroviral e resistência à droga.

\begin{tabular}{|c|c|c|}
\hline Países & $\begin{array}{l}\text { TDF / 3TC ou (FTC) / EFV preferidos ARVs de } \\
\text { primeira linha para o início do tratamento nas } \\
\text { diretrizes nacionais para adultos e adolescentes. }\end{array}$ & $\begin{array}{l}\text { Sistemas implantados para monitorar a } \\
\text { resistência aos medicamentos } \\
\text { antirretrovirais. }\end{array}$ \\
\hline Austrália & Dados não disponíveis & Dados não disponíveis \\
\hline Brasil & Sim Sim \\
\hline Canadá & Dados não disponíveis & Sim \\
\hline França & Dados não disponíveis & Dados não disponíveis \\
\hline Reino Unido & Dados não disponíveis & Dados não disponíveis \\
\hline Suécia & Dados não disponíveis & Dados não disponíveis \\
\hline
\end{tabular}

Fonte: UNAIDS (2020). 
Dos países analisados, quanto ao aspecto Adesão e Retenção, apenas o Brasil e o Canadá apresentam dados consolidados na plataforma, e esses apontam que ambos possuem uma política/estratégia nacional direcionada aos itens. Por outro lado, nenhum dos países abordados nesse estudo possui dados disponibilizados na plataforma sobre as Recomendações de diretrizes para populações-chave da OMS 2016 incluídas em políticas/planos nacionais. Ademais, apenas o Brasil e Canadá possuem dados quanto à PrEP oral, seguindo as recomendações nas diretrizes nacionais, ambos encontrando-se em fase de implantação (Quadro 4).

Quadro 4. Política ou estratégia de apoio à adesão e retenção do tratamento e presença de leis e profilaxias pré-exposição ao HIV, por país com sistema gratuito e universal de saúde.

\begin{tabular}{|c|c|c|l|l|}
\hline \multicolumn{3}{|c|}{ Adesão e Retenção } & \multicolumn{2}{c|}{ Leis e Profilaxia Pré Exposição } \\
\hline Países & $\begin{array}{l}\text { Política / estratégia } \\
\text { nacional de apoio à } \\
\text { adesão. }\end{array}$ & $\begin{array}{l}\text { Política / estratégia } \\
\text { nacional de retenção } \\
\text { em TARV }\end{array}$ & $\begin{array}{l}\text { Recomendações de } \\
\text { diretrizes para } \\
\text { populações-chave da } \\
\text { OMS 2016 incluídas na } \\
\text { política / planos } \\
\text { nacionais }\end{array}$ & $\begin{array}{l}\text { Recomendação da OMS } \\
\text { sobre PrEP oral adotada } \\
\text { nas diretrizes nacionais } \\
\text { do país }\end{array}$ \\
\hline Austrália & Dados não disponíveis & Dados não disponíveis & Dados não disponíveis & Dados não disponíveis \\
\hline Brasil & Sim & Sim & Dados não disponíveis & $\begin{array}{l}\text { Sim, foram desenvolvidas e } \\
\text { estão sendo implementadas }\end{array}$ \\
\hline Canadá & Sim & Sim & Dados não disponíveis & $\begin{array}{l}\text { Sim, foram desenvolvidas e } \\
\text { estão sendo implementadas }\end{array}$ \\
\hline França & Dados não disponíveis & Dados não disponíveis & Dados não disponíveis & Dados não disponíveis \\
\hline Reino Unido & Dados não disponíveis & Dados não disponíveis & Dados não disponíveis & Dados não disponíveis \\
\hline Suécia & Dados não disponíveis & Dados não disponíveis & Dados não disponíveis & Dados não disponíveis \\
\hline
\end{tabular}

Fonte: UNAIDS (2020).

Quanto ao sistema de informação de saúde em funcionamento, apenas o Brasil e o Canadá apresentam dados. Ademais, somente o Brasil apresenta dados disponibilizados sobre um sistema nacional de notificação de mortes individuais relacionadas ao HIV. Em contrapartida, o Canadá não apresenta esse modelo de sistema. Em relação à meta 90-90-90 da OMS, Brasil e o Canadá apresentaram Vigilância de casos de HIV como fonte de dados do número de pessoas que sabem seu status sorológico. Sobre o item coleta de dados do número de PHIV em TARV, o Brasil apresenta dados do programa, relatados principalmente por meio de identificadores, sendo, entretanto, que o Canadá agrega dados do programa de rotina dos sistemas de laboratório. Apesar disto, nenhum dos países possui dados disponibilizados na plataforma sobre a Triagem de TB recomendada em políticas/diretrizes nacionais para pessoas vivendo com HIV (Quadro 5). 
Quadro 5. Informações sobre saúde mortalidade, conhecimento de status sorológico, e triagem de co-infecção TB/HIV.

\begin{tabular}{|c|c|c|c|c|c|}
\hline \multicolumn{3}{|c|}{ Sistema de informação e Mortalidade } & \multicolumn{2}{|c|}{$90-90-90$} & TB/HIV \\
\hline Países & $\begin{array}{lr}\text { Sistema } & \text { de } \\
\text { informação } & \text { de } \\
\text { saúde } & \text { em } \\
\text { funcionamento } & \end{array}$ & 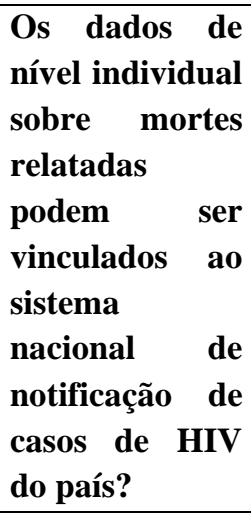 & $\begin{array}{l}\text { Fonte de dados } \\
\text { do número de } \\
\text { pessoas que } \\
\text { sabem seu } \\
\text { status } \\
\text { sorológico }\end{array}$ & $\begin{array}{lr}\text { Dados do } & \text { número } \\
\text { de pessoas vivendo } \\
\text { com HIV em } \\
\text { terapia } & \text { anti- } \\
\text { retroviral } & \end{array}$ & 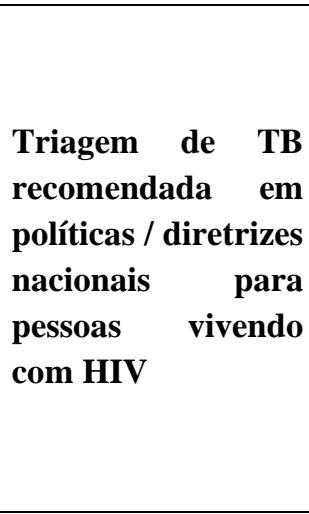 \\
\hline Austrália & $\begin{array}{l}\text { Dados não } \\
\text { disponíveis }\end{array}$ & $\begin{array}{l}\text { Dados não } \\
\text { disponíveis }\end{array}$ & $\begin{array}{l}\text { Dados não } \\
\text { disponíveis }\end{array}$ & $\begin{array}{l}\text { Dados não } \\
\text { disponíveis }\end{array}$ & $\begin{array}{l}\text { Dados não } \\
\text { disponíveis }\end{array}$ \\
\hline Brasil & Sim, eletrônico & Sim & $\begin{array}{l}\text { Vigilância de } \\
\text { casos de HIV }\end{array}$ & $\begin{array}{c}\text { Dados do programa, } \\
\text { relatados } \\
\text { principalmente por } \\
\text { meio de } \\
\text { identificadores } \\
\end{array}$ & $\begin{array}{l}\text { Dados não } \\
\text { disponíveis }\end{array}$ \\
\hline Canadá & Sim & Não & $\begin{array}{l}\text { Vigilância de } \\
\text { casos de HIV }\end{array}$ & $\begin{array}{c}\text { Dados do programa } \\
\text { de rotina dos } \\
\text { sistemas de } \\
\text { laboratório } \\
\end{array}$ & $\begin{array}{l}\text { Dados não } \\
\text { disponíveis }\end{array}$ \\
\hline França & $\begin{array}{l}\text { Dados não } \\
\text { disponíveis }\end{array}$ & $\begin{array}{l}\text { Dados não } \\
\text { disponíveis }\end{array}$ & $\begin{array}{l}\text { Dados não } \\
\text { disponíveis }\end{array}$ & $\begin{array}{l}\text { Dados não } \\
\text { disponíveis }\end{array}$ & $\begin{array}{l}\text { Dados não } \\
\text { disponíveis }\end{array}$ \\
\hline Reino Unido & $\begin{array}{l}\text { Dados não } \\
\text { disponíveis }\end{array}$ & $\begin{array}{l}\text { Dados não } \\
\text { disponíveis }\end{array}$ & $\begin{array}{l}\text { Dados não } \\
\text { disponíveis }\end{array}$ & $\begin{array}{l}\text { Dados não } \\
\text { disponíveis }\end{array}$ & $\begin{array}{l}\text { Dados não } \\
\text { disponíveis }\end{array}$ \\
\hline Suécia & $\begin{array}{l}\text { Dados não } \\
\text { disponíveis }\end{array}$ & $\begin{array}{l}\text { Dados não } \\
\text { disponíveis }\end{array}$ & $\begin{array}{l}\text { Dados não } \\
\text { disponíveis }\end{array}$ & $\begin{array}{l}\text { Dados não } \\
\text { disponíveis }\end{array}$ & $\begin{array}{l}\text { Dados não } \\
\text { disponíveis }\end{array}$ \\
\hline
\end{tabular}

Fonte: UNAIDS (2020).

\section{Discussão}

Diante do exposto, há um maior engajamento das ações adotadas pelo Brasil no tocante às recomendações da OMS de 2015 para a testagem do HIV, enquanto que, com relação ao Canadá, há uma parcialidade na adoção de tais recomendações, o que pode estar relacionado às particularidades de próprio Sistema de Saúde. Esses dois países, apesar de apresentarem algumas similaridades, possuem seus enfoques em medidas diferentes. Enquanto o Brasil amplia suas políticas públicas voltadas para a promoção da saúde, o Canadá direciona seus esforços na atuação dos profissionais frente aos determinantes sociais da saúde e a intersetorialidade (Heidemann, et al., 2018).

Com relação à gratuidade dos testes, podemos observar que somente o Brasil e o Canadá possuíam dados consolidados na plataforma. Entretanto, todos os países apresentam modalidades gratuitas de testagem para o diagnóstico do HIV (United Kindom, 2015; Sweden,2017; Haute Autorité de Santé, 2017; Australian Federation of Aids Organisations, [201]).

Além disto, as diretrizes atualizadas da OMS de 2018 sobre o uso da ARV, dizem respeito sobre as modificações no esquema terapêutico do HIV, dentre eles a adição do Dolutegravir (DGT) e Raltegravir (RAL) no arsenal medicamentoso de primeira linha (OMS, 2018). Assim, observa-se a adoção do Brasil às recomendações da OMS e, em contrapartida, o Canadá não desenvolve tais orientações para o tratamento do HIV, mas essas podem ser adotadas por responsabilidade das provinciais/ 
territórios (OMS, 2018). Os demais países, de acordo com suas próprias diretrizes, apresentam tais medicações como possibilidades terapêuticas; entretanto cabe ao profissional médico a escolha dessas medicações (Australasian Society for Hiv, Viral Hepatitis and Sexual Health Medicine, 2019; Conseil National du Sida et des Hépatites Virales, 2018; HIV I-Base, 2019;). Desta forma, cada país adota de maneira própria sua terapêutica levando em consideração não só as recomendações da OMS, mas a realidade local das PVHIV.

Com relação às políticas de testagem da carga viral, é possível observar o alinhamento do Brasil às determinações da OMS, tendo em vista a importância desse monitoramento. Algumas alterações patológicas podem estar relacionadas a uma maior carga viral necessitando, assim, de protocolos de investigação e acompanhamento das doenças relacionadas ou não ao HIV (Nogueira et al., 2019). Dessa forma, é benéfico esse acompanhamento, bem como o controle e adesão precoce ao tratamento (Nogueira et al., 2019).

Os esquemas para início do tratamento do HIV são vários, mas algumas combinações são recomendadas devido seu elevado valor de controle da carga viral e baixa sujeição de resistência, além da tolerabilidade da PVHI. No Brasil, a recomendação é de tratamento de todas as pessoas independentemente do estado clínico (Brasil, 2018). O esquema de tratamento deve ser direcionado para algumas situações ou públicos especiais. A combinação 3TC + TDF + EFV não é mais recomendada como tratamento de primeira linha, mas continua fazendo parte do portifólio e preconizado em algumas situações, tais como no caso de infecção pelo HIV em gestantes, coinfecção pela TB ou na impossibilidade do uso do Dolutegravir (Brasil, 2018; OMS, 2019).

Alguns sistemas são necessários para comprovar a eficácia do tratamento, dentre eles destaca-se o sistema de monitoramento de resistência aos medicamentos antirretrovirais. No Brasil, é recomendado a genotipagem do HIV disponível no SUS, por meio da Rede Nacional de Genotipagem (Renageno) (Brasil, 2019). Todavia, essa investigação só é realizada em algumas situações especiais. Entretanto, no Canadá, desde 1998, com a Criação do Programa Canadense de Vigilância de Cepas de HIV e Resistência a Medicamentos (Programa SDR), é possível monitorar os subtipos do HIV e a resistência às drogas PVHIV em pré-tratamento (Canadá, 2017).

A adesão e a retenção ao tratamento são dois dos princípios norteadores do pacto pelo fim do HIV, a meta 90-90-90 da UNAIDS. É importante dar seguimento ao tratamento do HIV de forma integrada e simultânea aos sistemas de promoção e monitoramento da adesão e retenção, fazendo destes a garantia do cuidado continuado e suporte em saúde individualizados para todos as PVHIV (Loch et al., 2018). No Brasil, uma das abordagens adotadas é a cascata de cuidado continuado, no qual se utilizam modelos matemáticos que demonstram o acesso à rede de saúde, além de desentrelaçar o diagnóstico do tratamento e evidenciar os serviços de saúde (Brasil, 2018). No Canadá, as diretrizes também abordam a adesão e retenção ao tratamento. Uma das suas formas de melhorar tais parâmetros, foi o pioneirismo da campanha Indetectável = Intransmissível (I=I), na qual a PVHIV em tratamento e com carga viral indetectável não transmite a doença, reduzindo assim o estigma (Canad's Suorce for Hiv and Hepatitis C Information, 2019).

A PreP, mecanismo recente de combate ao HIV, mostra-se importante em superar alguns obstáculos que limitam a utilização dos outros métodos, principalmente o preservativo masculino, tornando-se também um eficaz instrumento de enfrentamento à epidemia (Zucchi et al., 2018). Tanto o Brasil quanto o Canadá apresentam diretrizes que incorporam a PreP oral nas possibilidades de esquemas de prevenção ao HIV, sendo utilizados os mesmos medicamentos Tenofovir (TDF) e Emtricitabina (FTC) e sendo essa abordagem direcionada a um público específico, ou seja, aqueles que apresentam maior risco de contágio (Brasil, 2018; Canad's Suorce for Hiv and Hepatitis C Information, 2019).

Os Sistemas de Informação de Saúde apresentam-se como uma importante ferramenta para a criação e direcionamento de políticas públicas voltadas para determinados setores; entretanto, não basta apenas um serviço bem desenvolvido, mas também profissionais capacitados para sua utilização (Silva, 2016). No Brasil, esses sistemas são integrados 
pelo DATASUS (Sistema de Informação do SUS) e disponibilizados na plataforma online TABNET (Brasil, [201-]b). Apesar da base de dados da UNAIDS não especificar qual o modelo adotado no sistema de informação do Canadá, existe uma corporação sem fins lucrativos relacionada ao Governo responsável pelas coletas, diretamente nas províncias e territórios, e disponibilização dos dados, denominado Instituto Canadense de Informação em Saúde (Canadian Institute for Health Information, 2020).

Com relação aos dados sobre mortalidade relacionados ao HIV, há oposição entre o Brasil e o Canadá, segundo o que foi disponibilizado na plataforma da UNAIDS. Essa possibilidade dessa discordância pode possuir relação com o tipo de sistema de informação, o qual apresenta-se como vantagem o eletrônico, pois de acordo com OMS/OPAS o modelo brasileiro é um dos mais completos do mundo (Lima et al., 2015).

Quanto às metas 90-90-90 da UNAIDS, apesar de Brasil e Canadá apresentarem fonte de dados similares sobre o número de pessoas que sabem seu "status" sorológicos, os dados referentes à utilização da TARV por pessoas vivendo com HIV são obtidos de formas distintas: enquanto o Brasil cruza os dados a partir dos identificadores em saúde, o Canadá coleta tais dados nos programas de rotinas dos sistemas de laboratório. Esse fato pode repercutir na qualidade dos dados e velocidade em que são apresentados.

Com relação a coinfecção da Tuberculose, apesar de os dados não estarem disponíveis no momento da coleta, no Brasil é recomendado que todas as pessoas com confirmação do diagnóstico de infecção pelo vírus HIV sejam investigadas para a coinfecção pela TB. Essa investigação, em um primeiro momento, está relacionada com o questionamento sobre os principais sintomas da TB no ato das consultas (Brasil, 2018).

Com relação às limitações deste estudo, pode-se descartar que dos países envolvidos, somente o Brasil e o Canadá possuíam dados consolidados na Plataforma da UNAIDS referentes ao ano de 2019. Outra limitação é a existência de diretrizes nos países abordados, mas sem consolidação no site da UNAIDS.

\section{Conclusão}

A epidemia causada pelo vírus HIV continua sendo o alvo de várias políticas públicas de saúde, sejam estabelecidas por órgãos internacionais ou mesmo por agentes nacionais, que visam o reestabelecimento da saúde do indivíduo acometido e a eliminação do estigma. Os avanços tecnológicos que ocorreram ao longo dos anos mudaram o curso de doença aguda para crônica e com isso foi necessária a criação de diretrizes e políticas públicas que melhorem a qualidade de vida das PVHIV.

Este trabalho demonstrou a importância e os esforços dos países em seguir as recomendações da OMS para o enfrentamento do vírus, bem como evidenciou uma problemática relacionado à coleta ou disponibilidade dos dados de alguns países que possuem o sistema universal de saúde. Ademais, pode-se observar que o país que apresenta os dados melhor consolidados e alinhado às recomendações da OMS é o Brasil, entre os que possuem sistema universal de saúde.

Entretanto, ainda há muito a se fazer no que diz respeito à coleta e fortalecimento da base de dados da UNAIDS, bem como ao combate ao HIV. Assim, é importante que haja uma conformidade no enfrentamento ao vírus, respeitando as questões de regionalidade, a fim de realizar a meta 90-90-90 e pôr fim à epidemia.

Sugere-se que periodicamente novas pesquisas sobre a temática venham a público com intuito de atualização constante dos levantamentos, favorecendo difusão técnico-científica e ações de políticas públicas.

\section{Referências}

Agostini, R., Rocha, F., Melo, E., \& Maksud, I. (2019). A resposta brasileira à epidemia de HIV/AIDS em tempos de crise. Ciência \& Saúde Coletiva, 24(12), 4599-4604. 
Australasian Society For Hiv, Viral Hepatitis And Sexual Health Medicine (ASHM) (2019). Antiretroviral drugs and other therapies in HIV patients: recommended regimens for the treatment of HIV infection. 2019. <https://hivmanagement.ashm.org.au/antiretroviral-drugs/recommended-regimens-fortreatment-of-hiv-infection/>.

Australian Federation of Aids Organisations (AFAO). Getting tested for HIV. [201-] <https://www.afao.org.au/about-hiv/getting-tested-for-hiv/>

Brandão, J. R. D. M. (2019). A atenção primária à saúde no Canadá: realidade e desafios atuais. Cadernos de Saúde Pública, 35, e00178217.

Brasil. Constituição da República Federativa do Brasil de 1988. Brasília, DF: Senado Federal. 1988. <http://www.planalto.gov.br/ccivil_03/constituicao/constituicao.htm>.

Brasil. Ministério da Saúde. Departamento de Doenças de Condições Crônicas e Infecções Sexualmente Transmissíveis. Diretrizes Nacionais de Prevenção Combinada em HIV/AIDS. [201-]a. <http://www.aids.gov.br/pt-br/gestores/organizacao-dos-servicos/diretrizes-nacionais-de-prevencao-combinada-emhivaids>.

Brasil. Ministério da Saúde. INFORMAÇÕES de Saúde (TABNET). <http://www2.datasus.gov.br/DATASUS/index.php?area=02>.

Brasil. Ministério da Saúde. Secretaria de Vigilância em Saúde. Departamento de Vigilância, Prevenção e Controle das Infecç̃es Sexualmente Transmissíveis, do HIV/AIDS e das Hepatites Virais. Protocolo Clínico e Diretrizes Terapêuticas para Manejo da Infecção pelo HIV em Adultos / Ministério da Saúde, Secretaria de Vigilância em Saúde, Departamento de Vigilância, Prevenção e Controle das Infecções Sexualmente Transmissíveis, do HIV/AIDS e das Hepatites Virais. - Brasília: Ministério da Saúde, 2018.

Brasil. Ministério da Saúde. Secretaria de Vigilância em Saúde. Departamento de Doenças de Condições Crônicas e Infecções Sexualmente Transmissíveis (DCCI). Manual técnico para avaliação de exames de genotipagem do HIVI Ministério da Saúde, 2019.

Canad's Suorce for Hiv and Hepatitis C Information (CATIE) (2019). Oral pre-exposure prophylaxis (PrEP). <https://www.catie.ca/en/factsheets/prevention/pre-exposure-prophylaxis-prep>.

Canada. Public Health Agency of Canada (2017). Update on HIV-1 Strain and Transmitted Drug Resistance in Canada: 2012-2013. Centre for Communicable Diseases and Infection Control, Public Health Agency of Canada. <https://www.canada.ca/content/dam/phacaspc/documents/services/publications/diseasesconditions/hiv-canadian-strain-drug-resistance-surveillance-2012-2013/hiv-canadian-strain-drug-resistance-surveillance-2012-2013.pdf>.

Canada. Public Health Agency of Canada (2019). Canada's Health Care System. <https://www.canada.ca/en/health-canada/services/health-caresystem/reports-publications/health-care-system/canada.html>.

Canadian Institute for Health Information (2020). CIHI's Annual Report, 2019-2020.Ottawa, ON: CIHI; 2020. <https://www.cihi.ca/sites/default/files/document/cihi-annual-report-2019-2020-en.pdf〉.

Conseil National du Sida et des Hépatites Virales (CNS-ANRS) (2018). Prise en charge médicale des personnes vivant avec le VIH: Suivi de l'adulte vivant avec le VIH et organisation des soins (avril 2018). <https://cns.sante.fr/wp-content/uploads/2018/05/experts-vih_suivi.pdf>.

Cordilha, A. C., \& Lavinas, L. (2018). Transformações dos sistemas de saúde na era da financeirização. Lições da França e do Brasil. Ciência \& Saúde Coletiva, 23, 2147-2158.

Duckett, S. (2018). Expanding the breadth of Medicare: learning from Australia. Health Economics, Policy and Law, 13(3-4), 344-368.

Fundação Oswaldo Cruz - FIOCRUZ ([201-].). A epidemia da AIDS através do tempo. <http://www.ioc.fiocruz.br/aids20anos/linhadotempo.html>.

Garcia, M. S. M. P. \& Gonçalves, A. M. S. (2020). O modelo de saúde pública no Reino Unido. Intr@ciência: Revista Cientifica, 19 (1): 1-8.

Haute Autorité De Santé (2017). Évaluation Économique et santé publique. Service Communication - Information. Synthèse, conclusions et recommandations. $41 \quad$ p. <https://www.hassante.fr/upload/docs/application/pdf/201703/dir2/reevaluation_de_la_strategie_depistage_vih__synthese_conclusions_reco.pdf $>$.

Heidemann, I. T. S. B., Cypriano, C. D. C., Gastaldo, D., Jackson, S., Rocha, C. G., \& Fagundes, E. (2018). Estudo comparativo de práticas de promoção da saúde na atenção primária em Florianópolis, Santa Catarina, Brasil e Toronto, Ontário, Canadá. Cadernos de Saúde Pública, 34, e00214516.

HIV I-Base (2019). Introduction to ART: Octuber 2019. 〈https://i-base.info/guides/wp-content/uploads/2019/09/Intro-to-ART-Oct-2019.pdf>.

Lima, A. C., Januário, M. C., Lima, P. T., \& de Moura, W. (2015). DATASUS: o uso dos Sistemas de Informação na Saúde Pública. Refas-Revista Fatec Zona Sul, 1(3), 16-31.

Loch, A. P., Nemes, M. I. B., Santos, M. A., Alves, A. M., Melchior, R., Basso, C. R., Caraciolo, J. M. M., Alves, M. T. S. S. B., Castanheira, E. R. L., Carvalho, W. M. E. S., Kehrig, R. T., \& Monroe, A. A. (2018). Avaliação dos serviços ambulatoriais de assistência a pessoas vivendo com HIV no Sistema Único de Saúde: estudo comparativo 2007/2010. Cadernos de Saúde Pública, 34, e00047217.

Menezes, E. L. C. D., Scherer, M. D. D. A., Verdi, M. I., \& Pires, D. P. D. (2017). Modos de produzir cuidado e a universalidade do acesso na atenção primária à saúde. Saúde e Sociedade, 26, 888-903.

Miranda, L. O., Araújo, G. B. F., Furtado, D., Carvalho, M. L., da Silva, S. M. F., de Melo Moreira, A., \& de Freitas, D. R. J. (2017). Aspectos epidemiológicos da coinfecção Tuberculose/HIV no Brasil: revisão integrativa. Revista Prevenção de Infecção e Saúde, 3(3): 59-70.

Nogueira, L. F. R., Pellegrino, P., Duarte, A. D. S., Inoue, S. R. V., \& Marqueze, E. C. (2019). Transtornos mentais comuns estão associados a maior carga viral em pessoas vivendo com HIV. Saúde em Debate, 43, 464-476.

Nunes Júnior, S. S., \& Ciosak, S. I. (2018). Terapia antirretroviral para HIV/AIDS: o estado da arte. Revista de enfermagem UFPE on line, 12 (4): $1103-1111$. 
Research, Society and Development, v. 10, n. 2, e37310212574, 2021

(CC BY 4.0) | ISSN 2525-3409 | DOI: htttp://dx.doi.org/10.33448/rsd-v10i2.12574

Organização das Nações Unidas - ONU. Joint United Nations Programme on HIV/AIDS - UNAIDS. Prevenção Combinada. [201-]. <https://unaids.org.br/prevencao-combinada〉.

Organização das Nações Unidas (2016a. Joint United Nations Programme on HIV/AIDS - UNAIDS. Atualização sobre a AIDS no mundo. <https://unaids.org.br/2016/05/17-milhoes-de-pessoas-em-tratamento/>.

Organização das Nações Unidas (2016b). Joint United Nations Programme on HIV/AIDS - UNAIDS. A ONU e a resposta à AIDS no Brasil. <https://unaids.org.br/wp-content/uploads/2016/03/A-ONU-e-a-resposta-PORTUGU\%C3\%8AS.pdf>.

Organização Mundial da Saúde (OMS) (2018). Recomendações atualizadas sobre regimes anti-retrovirais de primeira e segunda linha e profilaxia pósexposição e recomendações sobre o diagnóstico precoce de HIV em bebês: orientação provisória. Genebra: Organização Mundial da Saúde. <https://apps.who.int/iris/rest/bitstreams/1168419/retrieve>.

Organização Mundial da Saúde (OMS) (2019). Atualização de recomendações sobre primeira e segunda linha regimes antirretrovirais: Tratamento do HIV Genebra: Organização Mundial da Saúde. <https://apps.who.int/iris/bitstream/handle/10665/325892/WHO-CDS-HIV-19.15-eng.pdf?ua=1>.

Organização Pan Americana de Saúde/Organização Mundial de Saúde (OPAS/OMS) (2017). Folha informativa - HIV/AIDS. Organização Pan-Americana de Saúde: Brasil. Nov/2017. <https://www.paho.org/bra/index.php?option=com_content\&view=article\&id=5666:folha-informativa-hiv-aids\&Itemid=812> .

Pereira, A. S., Shitsuka, D. M., Parreira, F. J., \& Shitsuka, R. (2018). Metodologia da pesquisa científica. <http://repositorio.ufsm.br/bitstream/handle/1/15824/Lic_Computacao_Metodologia-Pesquisa-Cientifica.pdf?sequence=1>.

Silva, L. B. (2016). Sistemas de Informação em Saúde como ferramenta para gestão do SUS. Caderno Saúde e Desenvolvimento. 8 (5): 52-62.

Sindicato Médico do Rio Grande do Sul (SIMERS) (2016). Conheça o "SUS" de outros cinco países. <http://www.simers.org.br/noticia/conheca-o-sus-deoutros-cinco-paises>.

Sweden.Barring The Way To Health. 2017. <http://legalbarriers.peoplewithhiveurope.org/country/sweden>.

United Kindom. Public Health England (2015). SJ Westrop, T Hartney, F McNeal, J Anderson, N Gill and A Nardone. HIV Testing and Self-Testing: Information update November 2015. PHE publications gateway, (2014001): 1-14. 〈https://www.gov.uk/government/publications/hiv-self-testing>.

World Health Organization (WHO) (2016). Global tuberculosis report. WHO report 2016. [Internet]. Geneva: World Health Organization. <http://www.who.int/tb/publications/global_report/gtbr2016_executive_summary.pdf?ual>.

Zucchi, E. M., Grangeiro, A., Ferraz, D., Pinheiro, T. F., Alencar, T., Ferguson, L., Estevam, D. L., \& Munhoz, R. (2018). Da evidência à ação: desafios do Sistema Único de Saúde para ofertar a profilaxia pré-exposição sexual (PrEP) ao HIV às pessoas em maior vulnerabilidade. Cadernos de Saúde Pública, 34(7), e00206617. 